\title{
Folic acid supplementation in children with sickle cell disease: study protocol for a double-blind randomized cross-over trial
}

Brock A. Williams ${ }^{1,2}$, Heather McCartney ${ }^{3}$, Erin Adams ${ }^{4}$, Angela M. Devlin ${ }^{2,3}$, Joel Singer ${ }^{5,6}$, Suzanne Vercauteren ${ }^{2,3,7}$, John K. Wu ${ }^{2,3}$ and Crystal D. Karakochuk ${ }^{1,2^{*}}$ (D)

\begin{abstract}
Background: Sickle cell disease (SCD) is a genetic disorder which causes dysfunctional red blood cells (RBC) and is thought to increase requirements for folate, an essential B vitamin, due to increased RBC production and turnover in the disease. High-dose supplementation with 1-5 mg/d folic acid, synthetic folate, has been the standard recommendation for children with SCD. There is concern about whether children with SCD need such high doses of folic acid, following mandatory folic acid fortification of enriched grains in Canada, and advancements in medical therapies which extend the average lifespan of RBCs. In animal and human studies, high folic acid intakes (1 mg/d) have been associated with accelerated growth of some cancers, and the biological effects of circulating unmetabolized folic acid (UMFA), which can occur with doses of folic acid $\geq 0.2 \mathrm{mg} / \mathrm{d}$, are not fully understood. The objective of this study is to determine efficacy of, and alterations in folate metabolism from high-dose folic acid in children with SCD during periods of folic acid supplementation versus no supplementation.

Methods: In this double-blind randomized controlled cross-over trial, children with SCD ( $n=36$, aged 2-19 years) will be randomized to either receive $1 \mathrm{mg} / \mathrm{d}$ folic acid, the current standard of care, or a placebo for 12 weeks. After a 12-week washout period, treatments will be reversed. Total folate concentrations (serum and RBC), different folate forms (including UMFA), folate-related metabolites, and clinical outcomes will be measured at baseline and after treatment periods. The sum of the values measured in the two periods will be calculated for each subject and compared across the two sequence groups by means of a test for independent samples for the primary (RBC folate concentrations) and secondary (UMFA) outcomes. Dietary intake will be measured at the beginning of each study period.
\end{abstract}

Discussion: As the first rigorously designed clinical trial in children with SCD, this trial will inform and assess current clinical practice, with the ultimate goal of improving nutritional status of children with SCD.

Trial registration: ClinicalTrials.gov NCT04011345. Registered on July 8, 2019

Keywords: Sickle cell disease, Pediatrics, Nutrition, Folic acid, Micronutrient supplementation, Randomized control trial

\footnotetext{
* Correspondence: crystal.karakochuk@ubc.ca

${ }^{1}$ Food, Nutrition, and Health, Faculty of Land and Food Systems, The

University of British Columbia, 2205 East Mall, Vancouver, British Columbia

V6T 1Z4, Canada

${ }^{2}$ BC Children's Hospital Research Institute, 950 W 28th Avenue, Vancouver,

British Columbia V5Z 4H4, Canada

Full list of author information is available at the end of the article
}

(c) The Author(s). 2020 Open Access This article is licensed under a Creative Commons Attribution 4.0 International License, which permits use, sharing, adaptation, distribution and reproduction in any medium or format, as long as you give appropriate credit to the original author(s) and the source, provide a link to the Creative Commons licence, and indicate if changes were made. The images or other third party material in this article are included in the article's Creative Commons licence, unless indicated otherwise in a credit line to the material. If material is not included in the article's Creative Commons licence and your intended use is not permitted by statutory regulation or exceeds the permitted use, you will need to obtain permission directly from the copyright holder. To view a copy of this licence, visit http://creativecommons.org/licenses/by/4.0/ The Creative Commons Public Domain Dedication waiver (http://creativecommons.org/publicdomain/zero/1.0/) applies to the data made available in this article, unless otherwise stated in a credit line to the data. 


\section{Administrative information}

Note: the numbers in curly brackets in this protocol refer to SPIRIT checklist item numbers. The order of the items has been modified to group similar items (see http://www.equator-network.org/reporting-guidelines/ spirit-2013-statement-defining-standard-protocol-itemsfor-clinical-trials/).

\begin{tabular}{|c|c|}
\hline Title $\{1\}$ & $\begin{array}{l}\text { Folic Acid Supplementation in Children } \\
\text { with Sickle Cell Disease: } \\
\text { Study Protocol for a Double-Blind Ran- } \\
\text { domized Cross-Over Trial }\end{array}$ \\
\hline Trial registration $\{2 \mathrm{a}$ and $2 \mathrm{~b}\}$. & Clinicaltrials.gov: NCT04011345 \\
\hline Protocol version $\{3\}$ & Version 5; December 10, 2019. \\
\hline Funding $\{4\}$ & $\begin{array}{l}\text { Canadian Institutes of Health Research } \\
\text { (ClHR) } \\
\text { Thrasher Research Fund }\end{array}$ \\
\hline Author details $\{5 a\}$ & $\begin{array}{l}\text { 'Food, Nutrition, and Health, Faculty of } \\
\text { Land and Food Systems, The University } \\
\text { of British Columbia, } 2205 \text { East Mall, } \\
\text { Vancouver, British Columbia, Canada, } \\
\text { V6T 1Z4 } \\
{ }^{2} \text { BC Children's Hospital Research } \\
\text { Institute, } 950 \text { W 28th Avenue, } \\
\text { Vancouver, British Columbia, Canada, } \\
\text { V5Z 4H4 } \\
{ }^{3} \text { Department of Pediatrics, Faculty of } \\
\text { Medicine, The University of British } \\
\text { Columbia, } 4480 \text { Oak Street, Vancouver, } \\
\text { British Columbia, Canada, V6H 3V4 } \\
{ }^{4} \text { Department of Pharmacy, BC } \\
\text { Children's Hospital, 4480 Oak Street, } \\
\text { Vancouver, British Columbia, Canada, } \\
\text { V6H 3V4 } \\
5 \text { School of Population and Public } \\
\text { Health, The University of British } \\
\text { Columbia, } 2206 \text { East Mall, Vancouver, } \\
\text { British Columbia, Canada, V6T 1Z3 } \\
6 \text { The Centre for Health Evaluation and } \\
\text { Outcome Science, St. Paul's Hospital, } \\
588 \text { - } 1081 \text { Burrard Street, Vancouver, } \\
\text { British Columbia, Canada, V6Z 1Y6 } \\
\text { 7Department of Pathology and } \\
\text { Laboratory Medicine, BC Children's } \\
\text { Hospital, 4480 Oak Street, Vancouver, } \\
\text { British Columbia, Canada, V6H 3V4 }\end{array}$ \\
\hline $\begin{array}{l}\text { Name and contact } \\
\text { information for the trial } \\
\text { sponsor }\{5 b\}\end{array}$ & $\begin{array}{l}\text { Canadian Institutes of Health Research } \\
\text { (CIHR) } \\
160 \text { Elgin Street, 10th FloorOttawa ON } \\
\text { K1A 0W9Canada } \\
\text { +1-613-941-2672 }\end{array}$ \\
\hline Role of sponsor $\{5 c\}$ & $\begin{array}{l}\text { The study sponsor and funders have no } \\
\text { role in the study design, collection, } \\
\text { management, analysis and } \\
\text { interpretation of data, writing of the } \\
\text { report or publication decisions. }\end{array}$ \\
\hline
\end{tabular}

\section{Introduction}

\section{Background and rationale $\{6 \mathrm{a}\}$}

Sickle cell disease (SCD) is a rare, inherited hemoglobinopathy that affects over 5000 Canadians, including 3000 children and youth [1]. In SCD, variants in the $\beta$-globin gene produce an abnormal sicklehemoglobin molecule (HbS), which forms a rigid sickle shape upon release of oxygen due to polymerization $[2,3]$. While the severity of disease can vary among homozygous and heterozygous genotypes, hallmarks of the disease include hemolytic anemia, vaso-occlusion, stroke, ischemic tissue damage, organ failure, and severe pain in the back, extremities, thorax, abdomen, and central nervous system [4-6]. Chronic hemolytic anemia and increased red blood cell (RBC) production and turnover in SCD are thought to increase the requirements of folate, a water-soluble family of compounds that are essential for erythropoiesis $[7,8]$. Naturally occurring folate is commonly found in foods such as leafy green vegetables, oranges, beans, and legumes [9], while dietary supplements and folate-fortified foods commonly contain folic acid (FA), the synthetic oxidized version of folate, due to its stability and higher bioavailability [10].

The Canadian Haemoglobinopathy Association recommends supplementation of $1-5 \mathrm{mg}$ per day ( $\mathrm{mg} /$ d) of FA in individuals with SCD in Canada [1], largely based on studies conducted between 1975 to 2001 that showed individuals with SCD had low blood serum or RBC folate concentrations [11-13]. The lowest recommended dose of $1 \mathrm{mg} / \mathrm{d}$ FA, however, provides 6 times more folate than is recommended for healthy children aged $1-3$ years [14].

The biological effects of FA are not fully understood. In order to be biologically active, FA is reduced to dihydrofolate by dihydrofolate reductase (DHFR). However, the capacity for DHFR to metabolize large amounts of FA may be limited [15]. Recent studies suggest that the maximal capacity for this process is much lower than was previously thought, so even intakes of FA as low as $0.2 \mathrm{mg}$ will leave an appreciable amount of unmetabolized folic acid (UMFA) to be taken up into circulation $[15,16]$.

There is limited evidence that FA supplementation improves hematological or clinical outcomes in individuals with SCD [7]. Effectiveness of FA supplementation was largely investigated in the 1970-1980s and presented inconclusive evidence [13, 17-20]. A 1983 trial among 117 Jamaican children with SCD aged 6 months to 4 years, the only trial eligible for inclusion in the Cochrane Review of FA supplementation in individuals with SCD, examined the effect of $5 \mathrm{mg} / \mathrm{d}$ FA versus a placebo [21]. Although authors observed an increase in serum folate levels (concentrations below $11 \mathrm{nmol} / \mathrm{L}$ were evident in $15 \%$ ( $n=6 / 39$ ) of children in the placebo group versus none of the folic acid group, while concentrations above $40 \mathrm{nmol} / \mathrm{L}$ were evident in $81 \%(n=33 / 41)$ of the folic acid group versus $15 \%$ in the placebo $(n=15 / 39)$ group) after 1 year in those treated with FA, no effect on hemoglobin, growth parameters, or other clinical events was observed [21]. The 
quality of the evidence, however, was low due to the high risk of bias in random sequence generation and incomplete data, making it difficult to draw conclusions from this trial [7].

There is mounting concern about whether Canadian children with SCD require high doses of FA, especially given the mandatory FA fortification of refined grains, specifically white flour, enriched pasta, and enriched corn meal, in Canada since 1998. It is estimated that Canadian children consume, on average, $331 \pm 123 \mu \mathrm{g}$ ( $n=2193$; children aged $1-3$ years) to $699 \pm 225 \mu \mathrm{g}$ ( $n=$ 2397; adolescent males aged 14-18 years) per day of dietary folate equivalents (from both naturally occurring folate and folic acid) [22]. With intake levels of this magnitude, the majority of Canadian children are predicted to meet the recommended dietary allowance for folate from food sources alone. Furthermore, the Canadian Health Measures Survey in 2011 showed that less than $1 \%$ of Canadians ( $n=5248,6-79$ years) had folate deficiency (RBC folate $<305 \mathrm{nmol} / \mathrm{L}$ ) and $40 \% \mathrm{had}$ high $\mathrm{RBC}$ folate concentrations (>1360 nmol/L) [23]. In Canadian children with SCD, a recent Canadian study ( $n=87$, age 2-17 years) reported that there was no evidence of serum folate deficiency among individuals supplemented with $1 \mathrm{mg} / \mathrm{d}$ FA [24].

Advancements in medical therapy, specifically the use of hydroxyurea, a medication which extends the average lifespan of RBCs from a mean of $4.1 \pm 2.71$ days to $21.3 \pm 6.44$ days through the promotion of fetal hemoglobin concentrations $[25,26]$, may also decrease folate requirements because of reduced RBC turnover. A 2017 study of US children with SCD $(n=72)$, the majority (96\%) of which were prescribed hydroxyurea, reported that discontinuation of $1 \mathrm{mg} / \mathrm{d}$ FA for $\sim 80$ days did not change RBC folate concentrations and mean RBC folate concentrations remained high (4 times higher than the suggested World Health Organization deficiency cutoff of $340 \mathrm{nmol} / \mathrm{L}$ [16]) after the discontinuation [27].

There is growing concern that higher FA intakes may lead to adverse health outcomes, as intakes of $1 \mathrm{mg} / \mathrm{d}$ FA have been associated with acceleration of mammary tumors in rats [28], and colorectal [29] and prostate [30] cancer in adults. There is also evidence that excess FA intakes may have adverse effects on metabolic health during development $[31,32]$ suggesting young children undergoing periods of rapid growth and development are especially vulnerable. The association of adverse health outcomes with high FA intake remains controversial, but debate has limited some countries from adopting mandatory nationwide FA fortification programs due to these concerns [33].

As no well-designed randomized controlled trial of FA supplementation on children with SCD has been conducted to date, the aim of this study is to determine if high-dose FA supplementation is efficacious, safe, and warranted in children with SCD.

\section{Objectives $\{7\}$}

The primary objective is to assess the efficacy of highdose FA supplementation by measuring the effect of 12 weeks of $1 \mathrm{mg} / \mathrm{d} \mathrm{FA}$ on RBC folate concentrations, serum folate concentrations, and clinical outcomes (occurrence of megaloblastic anemia and acute pain crises) in children with SCD, compared to placebo.

The secondary objective is to assess alterations in folate metabolism from high-dose FA supplementation by measuring the effect of 12 weeks of $1 \mathrm{mg} / \mathrm{d}$ FA on plasma UMFA concentrations, and folate-related metabolite concentrations (plasma $S$-adenosylmethionine, $S$ adenosylhomocysteine, total homocysteine, vitamin $B_{12}$, and methylmalonic acid) in children with SCD, compared to placebo.

We hypothesize that (1) none of the children will present with folate deficiency ( $\mathrm{RBC}$ folate $<340 \mathrm{nmol} / \mathrm{L}$ ) during the study period, (2) mean $\mathrm{RBC}$ folate concentrations will be similar following 12 weeks of FA or placebo supplementation, showing no benefit of FA supplementation, and (3) plasma UMFA concentrations will be higher following 12 weeks of FA supplementation compared to levels following the placebo supplementation.

\section{Trial design $\{8\}$}

This is a double-blind randomized controlled cross-over trial consisting of a $12 \pm 1$-week intervention period (treatment of $1 \mathrm{mg} / \mathrm{d}$ FA or placebo), followed by a $12 \pm$ 1 -week wash-out period and a reversal of treatments. The 12-week duration of the intervention and washout periods is based on the estimation that steady-state conditions of RBCs in children with SCD receiving hydroxyurea is reached before 80 days [27]. Approximately 60\% of the children with SCD at BC Children's Hospital are prescribed hydroxyurea [34]. The 12-week washout period will minimize the risk of any carryover effect of the first treatment.

The distinguishing advantage of a cross-over trial from a conventional parallel-arm trial is that each child will serve as his/her own control, thus reducing the bias of confounding variables (e.g., age, sex, dietary intake) [35]. This design will also allow us higher power (lower sample size requirement) to determine a statistically significant treatment effect [35].

A non-inferiority framework will be used to determine whether placebo is inferior or non-inferior to FA, the current standard, for the maintenance of red blood cell folate concentrations. 


\section{Methods: participants, interventions, and outcomes}

\section{Study setting $\{9\}$}

This trial will occur at BC Children's Hospital (Canada), an affiliate academic hospital of the University of British Columbia (Canada).

\section{Eligibility criteria $\{10\}$}

Individuals will be eligible for participation if (1) they have a confirmed diagnosis of SCD, (2) they are aged 2-19 years and attend BC Children's Hospital for medical care, and (3) they have received routine daily supplementation of FA for the prior 12 weeks.

Individuals will be excluded from participation if (1) they have received a blood transfusion in the previous 12 weeks, (2) they are allergic to any components of the supplements (cellulose, methylcellulose, magnesium stearate, and/or titanium dioxide), (3) they have presented with megaloblastic anemia in the previous 12 weeks, (4) they have current pulmonary, renal, and/or cardiac complications (severe or recurrent acute chest syndrome), (5) they routinely take medications known to interfere with B vitamin metabolism (chloramphenicol, methotrexate, metformin, sulfasalazine, phenobarbital, primidone, triamterene, barbiturates), (6) they are currently pregnant, planning to become pregnant in the next 9 months, or currently breastfeeding, (7) they have participated in a clinical research trial in the previous 30 days, (8) they have donated blood in the previous 30 days, or (9) they have an unstable medical condition or laboratory results.

\section{Who will take informed consent? \{26a\}}

Eligible individuals and their parents/legal guardians will be approached by the study coordinator (BAW) with information regarding the study at the out-patient hematology clinic at BC Children's Hospital. Written informed consent and child or adolescent assent, as applicable, will be obtained.

\section{Additional consent provisions for collection and use of participant data and biological specimens $\{26 \mathrm{~b}\}$ Not applicable \\ Interventions \\ Explanation for the choice of comparators $\{6 b\}$}

In this trial design, each participant will receive the current standard of care, $1 \mathrm{mg} / \mathrm{d} F A$, and a placebo comparator for $12 \pm 1$ weeks. As previous studies have illustrated children with SCD prescribed routine prophylactic FA $(1 \mathrm{mg} / \mathrm{d})$ continue to have mean red blood cell folate concentrations 4 times higher than deficiency cutoffs after discontinuation of FA supplementation [27], a placebo comparator was chosen given that treatment (supplementation) may be unnecessary in children, and folate concentrations are speculated to be adequate regardless of treatment group.

\section{Intervention description $\{11 a\}$}

Supplements are packaged in bottles containing 100 opaque capsules. The tablets, bottles, and labels on the bottle are identical in appearance except for a sticker which identifies the treatment group (A or B). Supplements will be dispensed from the BC Children's Hospital Pharmacy at the beginning of each intervention period. Supplements will contain $1 \mathrm{mg}$ FA or placebo, to be taken daily in the morning with food, for the 12 \pm 1 -week intervention periods. Individuals who cannot swallow capsules may open the capsules and add the powdered supplement to food products.

Supplements were manufactured by Natural Factors Nutritional Products Ltd. (Coquitlam, British Columbia, Canada), and a Notice of Authorization for the purposes of this clinical trial was obtained from the Natural and Non-Prescription Health Products Directorate of Health Canada on December 4, 2019.

\section{Criteria for discontinuing or modifying allocated interventions $\{11 b\}$}

Premature withdrawal from the study may occur due to use of other medications which are contraindicated (FAcontaining supplements), poor compliance with study protocols, participant request, and/or serious adverse events. Participants who are planning a pregnancy, or who have a confirmed pregnancy, during the intervention period will be removed from the clinical trial and will to return to receiving FA supplementation, as prescribed by their physician, according to the current standard of care. All previously collected data prior to withdrawal will be retained for analysis.

\section{Strategies to improve adherence to interventions $\{11 c\}$}

Adherence to study interventions will be monitored by the lead research pharmacist (EA) using capsule counts after each $12 \pm 1$-week study period and corroborated by supplement diaries which document date, time, and supplement consumption with or without food. The supplement diary will serve as a daily reminder to enhance adherence throughout the intervention periods.

\section{Relevant concomitant care permitted or prohibited during the trial $\{11 d\}$}

Consumption of other supplements containing FA is contraindicated for the duration of the study period. All other non-FA containing medications or natural health products approved or prescribed by a physician will be allowed for the duration of the study period. 


\section{Provisions for post-trial care \{30\}}

There will be medical follow-up for study participants after adverse events until symptoms have resolved or returned to baseline.

\section{Outcomes $\{12\}$}

Blood collection and processing A 3-h fasting venous blood sample will be collected at BC Children's Hospital and processed by the BC Children's Hospital BioBank at baseline and the start of each $12 \pm 1$-week time period for the duration of the study period (weeks $0,12,24$, and 36). A 3-h fast is needed to avoid the confounding influence of recent food or synthetic FA intakes on serum folate levels, which has been shown to have a peak response in serum at $80 \mathrm{~min}$ followed by subsequent declines in serum concentrations [36], while still detecting the presence of UMFA, which has been shown to be detectable for up to $10 \mathrm{~h}$ in fasted FA supplement users [37]. Caregivers and/or children will be advised not to take the supplement/placebo the day of the blood collection.

A total of $10 \mathrm{~mL}$ of venous blood will be collected in a 6-mL EDTA tube and 4-mL serum tube (BD Diagnostics). For preparation of whole blood hemolysate, whole blood $(0.3 \mathrm{~mL})$ will be removed from the $6 \mathrm{~mL}$ EDTA tube and diluted $1 / 11$ by adding $3.0 \mathrm{~mL}$ of a $1 \%$ ascorbic acid solution and subsequently incubated at $37^{\circ} \mathrm{C}$ for 30 min. Diluted whole blood will be aliquoted into three labeled microtubes. The remaining volume of the $6 \mathrm{~mL}$ EDTA tube will then be centrifuged at $3000 \mathrm{rpm}$ for 15 min at $4{ }^{\circ} \mathrm{C}$, and plasma and buffy coat will be collected. Plasma will be aliquoted into five labeled microtubes, and buffy coat will be aliquoted into a single labeled microtube.

The $4 \mathrm{~mL}$ serum tube will be left at room temperature for $\sim 30 \mathrm{~min}$ (until clotted), centrifuged at $3000 \mathrm{rpm}$ for $15 \mathrm{~min}$ at $4{ }^{\circ} \mathrm{C}$, and serum will be collected. Serum will be aliquoted into three labeled microtubes.

All aliquots will be stored at $-80^{\circ} \mathrm{C}$ until further analysis.

\section{Outcome measures}

Primary objective: efficacy of high-dose FA supplementation The primary outcome of the first study objective is total RBC folate concentrations (nmol/ L) measured at baseline and endline of the intervention periods (weeks $0,12,24$, and 36). RBC folate indicates longer term folate status, e.g., previous 3-4 months in healthy red blood cells, whereas serum folate reflects recent status or dietary intake [38]. Serum folate will therefore be measured as a secondary outcome at baseline and endline of the intervention periods (weeks $0,12,24$, and 36). Serum and RBC total folate will be assessed using two methods, as globally recommended
$[39,40]$ : serum folate using a microbiological assay [41] and $\mathrm{RBC}$ folate using liquid chromatography-mass spectrometry (LC-MS) [42]. RBC folate forms (tetrahydrofolate (THF), 5-methyl-THF, 5-formyl-THF, and 5,10methenyl-THF) will be measured using LC-MS [42]. Total RBC folate concentrations will be determined by subtracting serum folate from whole blood folate with a correction for hematocrit.

Secondary clinical outcomes, the occurrence of acute pain crises and megaloblastic anemia, will be measured at baseline and endline of the intervention periods (weeks 0 , 12, 24, and 36). Complete blood counts (CBC) will be prospectively collected from clinical blood work completed in tandem with research blood work. CBCs will be determined using an automated hematology analyzer. Megaloblastic anemia will be defined as an increase in MCV $>3 \mathrm{fL}$ and a reticulocyte count $<100 \times 10^{9} / \mathrm{L}$, and/or unexplained neutropenia (platelets $<100 \times 10^{9} / \mathrm{L}$ ) and thrombocytopenia (neutrophils $<1.5 \times 10^{9} / \mathrm{L}$ ).

Acute pain crises occurrence (defined as sudden onset of throbbing and continuous pain which can occur in one area of the body such as the back, joints, or arms/ legs, or can move throughout areas of the body) will be determined using participant self-report and will be quantified (number of events) and qualified (severity determined by self-management at home, management in Emergency Department of a hospital, or management during an in-patient admission to a hospital ward).

Secondary objective: alterations in folate metabolism from high-dose FA The primary outcome of the second study objective is plasma UMFA concentrations ( $\mathrm{nmol} /$ L) measured at baseline and endline of the intervention periods (weeks 0, 12, 24, and 36). Plasma UMFA concentrations will be measured using LC-MS [42], as UMFA is not incorporated into RBCs [43]. The proportion of children with detectable UMFA >0.2 nmol/L, and the proportion (\%) of UMFA that makes up plasma total folate will be determined.

Secondary outcome measures of folate-related metabolites ( $S$-adenosylmethionine, $S$-adenosylhomocysteine, and total homocysteine concentrations) [44, 45] will be measured using LC-MS $[46,47]$ at baseline and endline of the intervention periods (weeks $0,12,24$, and 36).

Other outcome measures will consist of $\mathrm{B}$ vitamin status (vitamins $\mathrm{B}_{12}$ and $\mathrm{B}_{6}$ ) measured at baseline and endline of the intervention periods (weeks $0,12,24$, and 36), and dietary folate intake measured at baseline of the intervention periods (weeks 0, 12, 24). For the determination of status of vitamin $B_{12}$, plasma methylmalonic acid (MMA), a marker of vitamin $B_{12}$ status [48], will be measured using LC-MS [49, 50], and plasma vitamin $B_{12}$ will be measured using an immunoanalyzer. For the determination of status of vitamin $B_{6}$, 
pyridoxal-5' -phosphate (nmol/L), a marker of vitamin $\mathrm{B}_{6}$, will be measured using HPLC [51].

Dietary folate intake in children will be estimated using three 24-h dietary recalls, with a 5-step multiple pass method [52], completed at the start of each $12 \pm 1$ week study period. Food models will be used to increase the accuracy of food portion estimates. Total dietary folate equivalents (DFEs) will be calculated, which takes into account the differences in bioavailability of dietary folate and synthetic FA ( $1 \mathrm{DFE}=1 \mu \mathrm{g}$ dietary folate or $0.6 \mu \mathrm{g}$ FA added to food) [53]. As the potential confounding bias of dietary FA intakes in children will be minimized due to the cross-over design of the trial (each child will serve as his/her own control), estimated dietary FA intakes are not planned to be included in any statistical analyses.

Gene variants associated with folate metabolism will also be measured at baseline (week 0). Genomic DNA will be extracted from buffy coat. MTHFR $(677 \mathrm{C}>\mathrm{T}$, rs 1801133, and $1298 \mathrm{~A}>\mathrm{C}, \quad r s 1801131)$ and DHFR (rs1643649 and rs70991108) variants [54], which are known to influence folate metabolism, will be detected using polymerase chain reaction (PCR) $[55,56]$.

\section{Participant timeline $\{13$}

\section{Sample size $\{14\}$}

Sample size was estimated using data from the recent Nguyen et al. [27] study in the USA to estimate means and standard deviation for $\mathrm{RBC}$ folate from children with SCD who had $1 \mathrm{mg} / \mathrm{d}$ FA discontinued. This population is similar to our clinical population in terms of national FA fortification policies and clinical management. A non-inferiority approach was used to determine the sample size needed to assess the efficacy of $1 \mathrm{mg} / \mathrm{d} \mathrm{FA}$ as compared to the placebo. Assuming a single group standard deviation in RBC folate of $150 \mathrm{ng} /$ $\mathrm{mL}(340 \mathrm{nmol} / \mathrm{L})$ observed post-FA discontinuation, a difference in means between groups of $30 \mathrm{ng} / \mathrm{mL}(68$ $\mathrm{nmol} / \mathrm{L}$ ) [27], power of 0.8 , alpha of 0.05 , and a noninferiority margin of $100 \mathrm{ng} / \mathrm{mL}(227 \mathrm{nmol} / \mathrm{L})$ determined based on clinical significance, 28 children (14 in each treatment order) are needed to confirm that the $\mathrm{RBC}$ folate concentrations are at most $100 \mathrm{ng} / \mathrm{mL}(227$ $\mathrm{nmol} / \mathrm{L}$ ) lower during the placebo period than during the FA supplementation period.

Sample size was rounded up to 36 children (18 in each treatment order) to account for attrition and to be powered to detect clinically meaningful differences in our secondary outcome (UMFA concentrations).

\section{Recruitment $\{15\}$}

Potential participants will first be provided a brief introduction to the study via email communication and later approached in-person in an outpatient clinic setting at BC Children's Hospital by the study coordinator (BAW). Informed consent and child/adolescent assent will be obtained in person.

\section{Assignment of interventions: allocation Sequence generation \{16a\}}

An independent research assistant from Natural Factors Nutritional Products Ltd. (Coquitlam, British Columbia, Canada) assigned blinding codes (A or B) to the FA and placebo supplements. The allocation sequence to treatment $\mathrm{A}$ or $\mathrm{B}$ was determined by a statistician unassociated with the study, under the direction of a clinical trialist (JS), via computer-generated random numbers in SAS statistical software, stratified in blocks of four to ensure roughly equal distribution of treatment order allocations during the study duration.

\section{Concealment mechanism \{16b\}}

The generated allocation sequence and blinding codes were transferred directly via encrypted email from the clinical trialist (JS) to the lead research pharmacist (EA) dispensing the treatments in order to maintain blinding of allocation.

\section{Implementation \{16c\}}

The lead research pharmacist (EA) will assign participants to treatment order based on the allocation sequence following the enrolment of participants by the blinded study coordinator (BAW).

\section{Assignment of interventions: blinding Who will be blinded $\{17 a\}$}

Clinicians/care providers, study personnel, outcome assessors, data analysts, and participants will be blinded to the allocation sequence. The sequence allocation will be kept confidential by research pharmacy personnel until full data analysis has been completed.

\section{Procedure for unblinding if needed $\{17 b\}$}

In an emergency situation, in which the health and safety of a participant is at risk, breaking the code of the double-blinded study may be done at the request of a medical practitioner responsible for the medical management of a participant to (1) to reveal treatment assignment to inform further medical treatment, (2) to provide information about the nature and risks of the particular treatment the participant is or has received, or (3) for the Principal Investigator to advise about the nature and risks associated with a particular treatment. The research pharmacy may make the randomization assignment result available to the Principal Investigator $(\mathrm{CDK})$, for communication to the requesting clinician, upon reasonable request. 
Data collection and management

Plans for assessment and collection of outcomes $\{18 a\}$

Data (baseline questionnaires, dietary assessment, clinical outcomes, and adherence) and biochemistry will be prospectively collected throughout the study period according to the participant timeline (Fig. 1). The baseline questionnaire will collect information on disease genotype, region of ancestry, age, current use of supplements and medications (specifically antibiotics, vitamin D, FA, other vitamins and minerals, and hydroxyurea), and history of pain crisis occurrence in the previous 12 weeks.

\section{Plans to promote participant retention and complete follow-up $\{18 b\}$}

The provision of incentives (\$25 gift card/study visit $\times 4$. study visits) are planned to promote retention of study participants. Study visits are also planned in conjunction with regular clinic appointments to limit the burden of participation and promote complete follow-up.

\section{Data management $\{19\}$}

Study data will be collected and managed using REDCap electronic data capture tools hosted at BC Children's Hospital Research Institute. Mandatory entry fields, range checks, and double entry in the database will contribute to the promotion of data quality. Quality audits of data will be conducted by research personnel once data collection is complete.

\section{Confidentiality $\{27\}$}

Data with personal identifiers will be stored on an encrypted, password-protected computer in a secure server space with the BC Children's Hospital Research Institute. A copy of the supplement prescription containing patient identifiers and subject ID, required for dispensing, will be stored under double-lock storage in the hospital research pharmacy. All other data will be de-linked to protect confidentiality. Hard copy data will be stored under double-lock storage for a minimum of 25 years after publication in accordance with Health

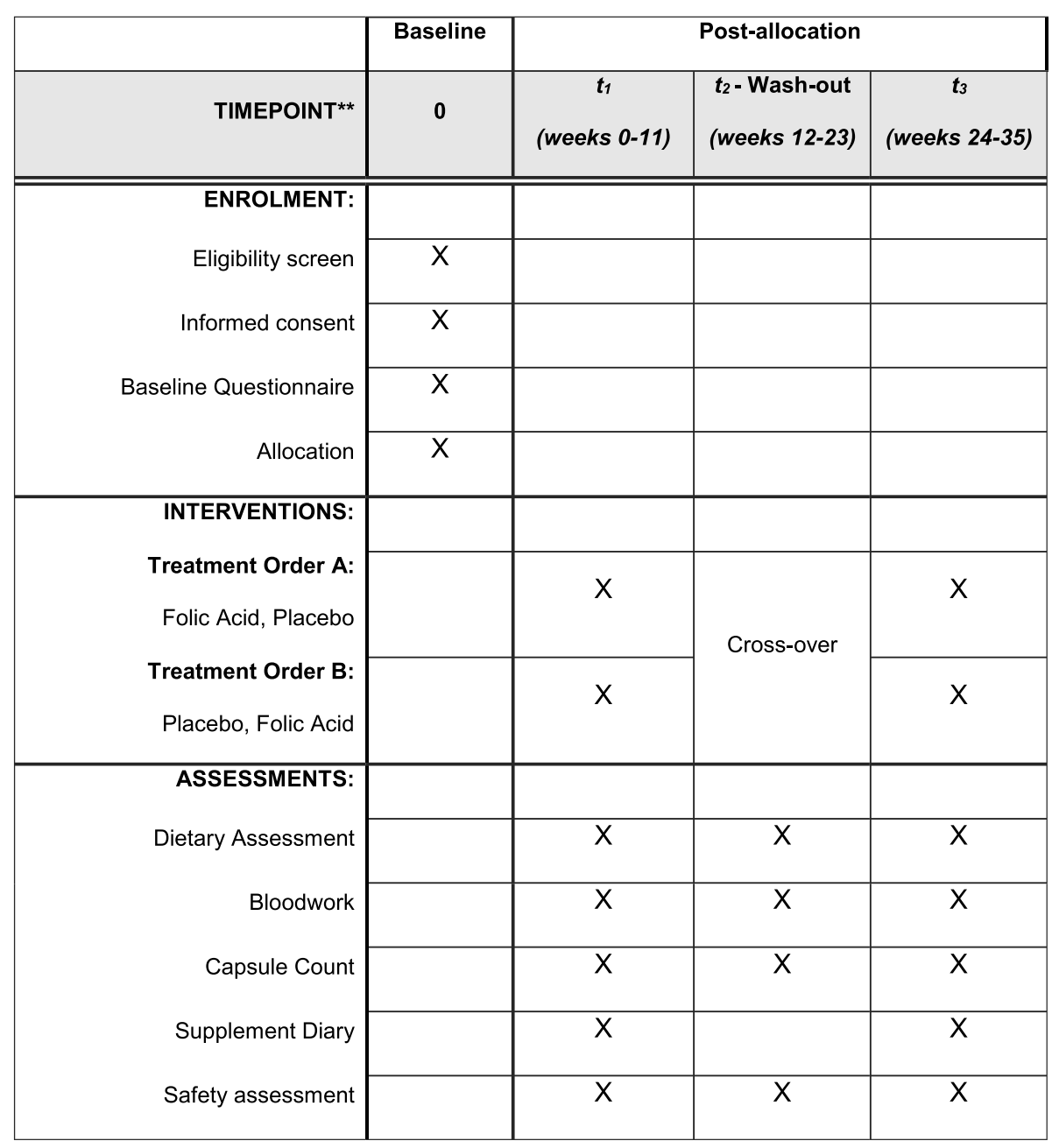

Fig. 1 Participant timeline 
Canada requirements. Computerized data will be password-protected and stored in the encrypted BC Children's Hospital Research Institute-maintained RedCap electronic data capture program via hospital network server. Biological samples will be stored in a locked freezer in the Principal Investigator's (CDK) laboratory at the University of British Columbia.

Plans for collection, laboratory evaluation, and storage of biological specimens for genetic or molecular analysis in this trial/future use $\{33\}$

In the current trial, genomic DNA will be extracted from buffy coat collected at baseline for the detection of MTHFR (677 C>T, rs 1801133, and $1298 \mathrm{~A}>\mathrm{C}$, rs1801131) and DHFR (rs1643649 and rs70991108) variants. No further genetic or molecular analysis is planned.

\section{Statistical methods \\ Statistical methods for primary and secondary outcomes $\{20 a\}$}

Intention-to-treat analyses, in which participants will be retained in their original assigned groups, will be performed using Stata 16 (Stata Corp, Texas). Twosided $p$ values less than 0.05 will indicate statistical significance.

First, we will confirm that the washout period was long enough to rule out a carryover effect by conducting a preliminary test: the sum of the values measured in the two periods (for RBC folate concentration) will be calculated for each subject and compared across the two sequence groups by means of a test for independent samples [35]. The 95\% CI of the difference in means between treatments will be compared to the noninferiority margin. If it does not exceed the margin, then we will support the hypothesis that placebo is noninferior to supplementation [35].

We will repeat the aforementioned analyses for our secondary outcomes (UMFA concentrations). We will also consider plasma UMFA $>0.2 \mathrm{nmol} / \mathrm{L}$ as "detectable" levels of UMFA (as reported in previous studies) [5759] and will calculate the proportion of children with concentrations $>0.2 \mathrm{nmol} / \mathrm{L}$ in each group. We will also measure and compare plasma UMFA as a proportion of total blood (\% of total blood) across groups. Lastly, we will compare blood folate forms across the groups in proportions of total folate, reduced folate forms, 5methyl-THF, and UMFA. The "total folate" group will represent the sum of THF, 5-methyl-THF, 5,10-methylTHF, 5-formyl-THF, and UMFA. The "reduced folate" group will represent the sum of THF, 5-methyl-THF, 5, 10-methenyl-THF, and 5-formyl-THF.
Interim analyses $\{21 b\}$

A full review of safety data (occurrence of megaloblastic anemia and acute pain crises, in comparison with baseline measures) will be completed by our independent Data Safety and Monitoring Board (DSMB) after a quarter of the participants $(n=9)$ have completed the first $12 \pm 1$-week treatment period to ensure the safety of the interventions. Primary outcome measures will not be analyzed at this time.

\section{Methods for additional analyses (e.g., subgroup analyses) $\{20 b\}$}

No subgroup or adjusted analyses are planned.

\section{Methods in analysis to handle protocol non-adherence and} any statistical methods to handle missing data $\{20 \mathrm{c}\}$

An intention-to-treat protocol will be used for data analysis. Multiple imputation will be used to correct for missing data, as appropriate [60].

Plans to give access to the full protocol, participant leveldata, and statistical code $\{31 \mathrm{c}\}$

The full study protocol is publicly available via ClinicalTrials.gov: NCT04011345. De-identified data and statistical code will be provided to researchers who provide a methodologically sound proposal, following receipt of a signed data access agreement.

\section{Oversight and monitoring}

\section{Composition of the coordinating center and trial steering} committee $\{5 d\}$

A multi-disciplinary steering committee was established to guide the research trial from conception to completion. Membership includes the Primary Investigator (CDK), the SCD Clinic Hematologist (JKW), and the SCD Nurse Clinician (HM). The steering committee will also lead knowledge translation planning activities. The data management team will consist of the study coordinator (BAW) and Principal Investigator (CDK).

\section{Composition of the data monitoring committee, its role and reporting structure $\{21 a\}$}

An independent DSMB consisting of three independent clinicians that, collectively, have experience in the management of patients with hemoglobinopathies/blood disorders and in the conduct and monitoring of randomized clinical trials has been established.

The purpose of the DSMB meetings is to review the conduct of the trial to date and assess safety of the study intervention. A full review of safety data (occurrence of megaloblastic anemia and acute pain crises, in comparison with baseline measures) will be completed after a quarter of the participants $(n=9)$ have completed the first $12 \pm 1$-week treatment period. This data will be 
supplied, in strict confidence, to the DSMB, together with any other analyses that the committee may request. This may include analyses of data from other comparable trials. In the light of this review, the DSMB will advise the TSC (Trial Steering Committee) if in its view the study should be discontinued due to safety concerns. As there is evidence that children with SCD maintain adequate $\mathrm{RBC}$ folate concentrations following discontinuation of prophylactic FA supplementation, it is expected that the study will continue until planned completion.

\section{Adverse event reporting and harms $\{22\}$}

Independent safety monitoring for the duration of the study will be continuous, with all adverse outcomes being reported during each $12 \pm 1$-week time period, according to protocol, to our DSMB, research ethics board, and health regulator.

\section{Frequency and plans for auditing trial conduct $\{23\}$}

Trial conduct will follow Good Clinical Practice (GCP) guidelines for the safe and effective undertaking of the clinic trial. The Trial Steering Committee will be in charge of auditing trial conduct, and reviewing trial processes and documents to ensure that research activities comply with the requirements of the protocol on an annual basis. It will review screening and consent documentation to ensure ethical trial conduct.

\section{Plans for communicating important protocol amendments to relevant parties (e.g., trial participants, ethical committees) $\{25\}$}

Any modifications to the protocol which may impact on the conduct of the study and potential benefit of the patient or may affect patient safety, including changes of study objectives, study design, patient population, sample sizes, study procedures, or significant administrative aspects, will be communicated to participants, investigators, research ethics board, regulators, registries, and journals, as applicable.

\section{Dissemination plans $\{31 \mathrm{a}\}$}

Trial results will be disseminated to healthcare professionals, the public, and other relevant groups via open-access peer-reviewed publications and through presentations of findings at both national and international conferences and symposia.

\section{Trial status}

Recruitment began February 2, 2020, and is expected to run until February 1, 2021. The current protocol version (version 5) is dated December 10, 2019.

\section{Abbreviations}

BC: British Columbia; CIHR: Canadian Institutes of Health Research;

DSMB: Data and Safety Monitoring Board; FA: Folic acid; RBC: Red blood cell; SAM: S-adenosylmethionine; SAH: S-adenosylhomocysteine; SCD: Sickle cell disease; TSC: Trial Steering Committee; UBC: University of British Columbia; UMFA: Unmetabolized folic acid

\section{Acknowledgements}

We thank Natural Factors Nutritional Products Ltd. (Coquitlam, British Columbia, Canada) for the in-kind donation of the compounded and packaged FA and placebo study supplements.

We are grateful for the expertise and commitment of our Data Safety and Monitoring Board Members, Dr. Nicholas Au, Dr. Amanda Li, and Dr. Douglas Morrison.

Authors' contributions $\{\mathbf{3 1 b}\}$

CDK, AMD, SV, and JKW were responsible for study conception. BAW, HM $E A, A M D, J S, S V, J K W$, and CDK were all involved in the protocol design and development. BAW and CDK wrote the first draft of the manuscript. All authors read and approved the final manuscript.

\section{Competing interests $\{28\}$}

The authors declare that they have no competing interests.

\section{Funding $\{4\}$}

Funding support is provided by project grants from the Canadian Institutes of Health Research and the Thrasher Research Fund. BAW is supported by a CIHR Frederick Banting and Charles Best Canada Graduate Scholarship Doctoral Award. AMD is supported by an Investigator Grant from BC Children's Hospital Research Institute. CDK is supported by a Michael Smith Foundation for Health Research Scholar Award. Funding agencies have no role in the design of the study, collection, analysis, and interpretation of data, or in the writing of manuscripts.

Availability of data and materials $\{29\}$

The de-identified datasets used and/or analyzed during the current study are available from the corresponding author on reasonable request.

Consent for publication $\{32\}$

Not applicable

Ethics approval and consent to participate $\{24\}$

Ethical approval was obtained from the University of British Columbia Clinical Research Ethics Board (H18-02981) on January 3, 2020. Written informed consent will be obtained from all participants. Child and adolescent assent will be obtained, as appropriate.

\section{Author details}

${ }^{1}$ Food, Nutrition, and Health, Faculty of Land and Food Systems, The University of British Columbia, 2205 East Mall, Vancouver, British Columbia V6T 1Z4, Canada. ${ }^{2}$ BC Children's Hospital Research Institute, 950 W 28th Avenue, Vancouver, British Columbia V5Z 4H4, Canada. ${ }^{3}$ Department of Pediatrics, Faculty of Medicine, The University of British Columbia, 4480 Oak Street, Vancouver, British Columbia V6H 3V4, Canada. ${ }^{4}$ Department of Pharmacy, BC Children's Hospital, 4480 Oak Street, Vancouver, British Columbia V6H 3V4, Canada. ${ }^{5}$ School of Population and Public Health, The University of British Columbia, 2206 East Mall, Vancouver, British Columbia V6T 1Z3, Canada. ${ }^{6}$ The Centre for Health Evaluation and Outcome Science, St. Paul's Hospital, 588 - 1081 Burrard Street, Vancouver, British Columbia V6Z 1Y6, Canada. ${ }^{7}$ Department of Pathology and Laboratory Medicine, BC Children's Hospital, 4480 Oak Street, Vancouver, British Columbia V6H 3V4, Canada.

Received: 19 May 2020 Accepted: 19 June 2020

Published online: 29 June 2020

\section{References}

1. The Canadian Haemoglobinopathy Association. Consensus statement on the care of patients with sickle cell disease in Canada. 2015.

2. Schnog JB, Duits AJ, Muskiet FA, Ten Cate H, Rojer RA, Brandjes DP. Sickle cell disease; a general overview. Neth J Med. 2004;62(10):364-74. 
3. Rees DC, Williams TN, Gladwin MT. Sickle-cell disease. Lancet. 2010; 376(9757):2018-31.

4. Kohne E. Hemoglobinopathies: clinical manifestations, diagnosis, and treatment. Dtsch Arztebl Int. 2011;108(31-32):532.

5. Piel FB, Steinberg MH, Rees DC. Sickle cell disease. N Engl J Med. 2017; 376(16):1561-73.

6. Al-Saqladi A-W, Cipolotti R, Fijnvandraat K, Brabin BJ. Growth and nutritional status of children with homozygous sickle cell disease. Ann Trop Paediatr. 2008;28(3):165-89.

7. Dixit R, Nettem S, Madan SS, Soe HHK, Abas ABL, Vance LD, et al. Folate supplementation in people with sickle cell disease. Cochrane Database Syst Rev. 2018;(3):CD011130.

8. Koury MJ, Ponka P. New insights into erythropoiesis: the roles of folate, Vitamin B 12, and iron. Annu Rev Nutr. 2004;24(1):105-31.

9. Chan Y-M, Bailey R, O'Connor DL. Folate. Adv Nutr. 2013;4(1):123-5.

10. Lamers Y, MacFarlane AJ, O'Connor DL, Fontaine-Bisson B. Periconceptional intake of folic acid among low-risk women in Canada: summary of a workshop aiming to align prenatal folic acid supplement composition with current expert guidelines. Am J Clin Nutr. 2018;108(6):1357-68.

11. Van Der Dijs FB, Schnog JJ, Brouwer DA, Velvis HJ, Van Den Berg GA, Bakker $\mathrm{AJ}$, et al. Elevated homocysteine levels indicate suboptimal folate status in pediatric sickle cell patients. Am J Hematol. 1998;59(3):192-8.

12. Kennedy TS, Fung EB, Kawchak DA, Zemel BS, Ohene-Frempong K, Stallings VA. Red blood cell folate and serum vitamin B12 status in children with sickle cell disease. J Pediatr Hematol Oncol. 2001;23(3):165-9.

13. Liu YK. Folic acid deficiency in sickle cell anaemia. Scand J Haematol. 1975; 14(1):71-9.

14. Otten JJ, Hellwig JPML. Dietary reference intakes: the essential guide to nutrient requirements. Washington D.C.: National Academies Press; 2006

15. Patanwala I, King MJ, Barrett DA, Rose J, Jackson R, Hudson M, et al. Folic acid handling by the human gut: implications for food fortification and supplementation. Am J Clin Nutr. 2014;100(2):593-9.

16. Kelly P, McPartlin J, Goggins M, Weir DG, Scott JM. Unmetabolized folic acid in serum: acute studies in subjects consuming fortified food and supplements. Am J Clin Nutr. 1997;65(6):1790-5.

17. Lindenbaum J, Klipstein FA. Folic acid deficiency in sickle-cell anemia. N Engl J Med. 1963;269(17):875-82.

18. Hendrickse RG, Barnes PM. Sickle cell anaemia: report of a therapeutic trial. West Afr Med J. 1966;15(2):55-64.

19. Alperin JB. Folic acid deficiency complicating sickle cell anemia: a study on the response to titrated doses of folic acid. Arch Intern Med. 1967;120(3) 298-306.

20. Watson-Williams EJ. Folic acid deficiency in sickle-cell anaemia. East Afr Med J. 1962;39:213-21.

21. Rabb LM, Grandison Y, Mason K, Hayes RJ, Serjeant B, Serjeant GR. A trial of folate supplementation in children with homozygous sickle cell disease. Br J Haematol. 1983;54(4):589-94.

22. Shakur YA, Garriguet D, Corey P, O'Connor DL. Folic acid fortification above mandated levels results in a low prevalence of folate inadequacy among Canadians. Am J Clin Nutr. 2010;92(4):818-25.

23. Colapinto $\mathrm{CK}, \mathrm{O}^{\prime} \mathrm{C}$ onnor DL, Tremblay MS. Folate status of the population in the Canadian Health Measures Survey. CMAJ. 2011;183(2):E100-6.

24. Martyres DJ, Vijenthira A, Barrowman N, Harris-Janz S, Chretien C, Klaassen RJ. Nutrient insufficiencies/deficiencies in children with sickle cell disease and its association with increased disease severity. Pediatr Blood Cancer. 2016;63(6):1060-4.

25. Ballas SK, Marcolina MJ, Dover GJ, Barton FB. Erythropoietic activity in patients with sickle cell anaemia before and after treatment with hydroxyurea. Br J Haematol. 1999;105(1995):491-6.

26. Steinberg MH, Chui DHK, Dover GJ, Sebastiani P, Alsultan A. Fetal hemoglobin in sickle cell anemia: a glass half full? Blood. 2014;123(4): 481-5.

27. Nguyen GKT, Lewis A, Goldener C, Reed B, Dulman RY, Yang E. Discontinuation of folic acid supplementation in young patients with sickle cell anemia. J Pediatr Hematol Oncol. 2017;39(6):470-2.

28. Manshadi SD, Ishiguro L, Sohn KJ, Medline A, Renlund R, Croxford R, et al. Folic acid supplementation promotes mammary tumor progression in a rat model. PLoS One. 2014;9(1):e84635.

29. Cole BF, Baron JA, Sandler RS, Haile RW, Ahnen DJ, Bresalier RS, et al. Folic acid for the prevention of colorectal adenomas: a randomized clinical trial. JAMA. 2007;297(21):2351-9.
30. Figueiredo JC, Grau MV, Haile RW, Sandler RS, Summers RW, Bresalier RS, et al. Folic acid and risk of prostate cancer: results from a randomized clinical trial. J Natl Cancer Inst. 2009;101(6):432-5.

31. Henderson AM, Tai DC, Aleliunas RE, Aljaadi AM, Glier MB, Xu EE, et al. Maternal folic acid supplementation with vitamin B12 deficiency during pregnancy and lactation affects the metabolic health of adult female offspring but is dependent on offspring diet. FASEB J. 2018;32(9):5039-50.

32. Yajnik CS, Deshpande SS, Jackson AA, Refsum H, Rao S, Fisher DJ, et al. Vitamin B12 and folate concentrations during pregnancy and insulin resistance in the offspring: the Pune Maternal Nutrition Study. Diabetologia. 2008;51(1):29-38.

33. Vollset SE, Clarke R, Lewington S, Ebbing M, Halsey J, Lonn E, et al. Effects of folic acid supplementation on overall and site-specific cancer incidence during the randomised trials: meta-analyses of data on 50000 individuals. Lancet. 2013;381(9871):1029-36.

34. Samson KLI, Mccartney H, Vercauteren SM, Wu JK, Karakochuk CD. Prevalence of vitamin D deficiency varies widely by season in Canadian children and adolescents with sickle cell disease. J Clin Med. 2018;7(2):E14.

35. Wellek $\mathrm{S}$, Blettner $\mathrm{M}$. On the proper use of the crossover design in clinical trials. Dtsch Arztebl Int. 2012;109(15):276-81.

36. Kelly P, McPartlin J, Scott J. A combined high-performance liquid chromatographic-microbiological assay for serum folic acid. Anal Biochem. 1996;238(2): 179-83.

37. Bailey RL, Mills JL, Yetley EA, Gahche JJ, Pfeiffer CM, Dwyer JT, et al. Unmetabolized serum folic acid and its relation to folic acid intake from diet and supplements in a nationally representative sample of adults aged $\geq 60 \mathrm{y}$ in the United States. Am J Clin Nutr. 2010 Jun 23;92(2):383-9.

38. WHO. Serum and red blood cell folate concentrations for assessing folate status in populations. Geneva: World Health Organization; 2015.

39. Pfeiffer CM, Sternberg MR, Fazili Z, Lacher DA, Zhang M, Johnson CL, et al. Folate status and concentrations of serum folate forms in the US population: National Health and Nutrition Examination Survey 2011-2. Br 」 Nutr. 2015;113:1965-77.

40. Yetley EA, Pfeiffer CM, Phinney KW, Fazili Z, Lacher DA, Bailey RL, et al, Biomarkers of folate status in NHANES: a roundtable summary. Am J Clin Nutr. 2011:94(1):303S-12S

41. Molloy AM, Scott JM. Microbiological assay for serum, plasma, and red cell folate using cryopreserved, microtiter plate method. Methods Enzymol. 1997;281:43-53.

42. Pfeiffer CM, Fazili Z, McCoy L, Zhang M, Gunter EW. Determination of folate vitamers in human serum by stable-isotope-dilution tandem mass spectrometry and comparison with radioassay and microbiologic assay. Clin Chem. 2004:50(2):423-32.

43. Hu J, Wang B, Sahyoun NR. Application of the key events dose-response framework to folate metabolism. Crit Rev Food Sci Nutr. 2016;56(8):1325-33.

44. Clarke S, Banfield K. S-adenosylmethionine-dependent methyltransferases. In: Carmel R, Jacobsen DW, editors. Homocysteine in health and disease. Cambridge: Cambridge Press; 2001. p. 3-78.

45. Herbig K, Chiang EP, Lee LR, Hills J, Shane B, Stover PJ. Cytoplasmic serine hydroxymethyltransferase mediates competition between folate-dependent deoxyribonucleotide and S-adenosylmethionine biosyntheses. J Biol Chem. 2002;277(41):38381-9.

46. Finkelstein JD. The metabolism of homocysteine: pathways and regulation. Eur J Pediatr. 1998;157:S40-4.

47. Arning E, Bottiglieri T. Quantitation of S-adenosylmethionine and Sadenosylhomocysteine in plasma using liquid chromatography-electrospray tandem mass spectrometry. In: Methods in molecular biology; 2016. p. 255-62.

48. Carmel R. Biomarkers of cobalamin (vitamin B-12) status in the epidemiologic setting: a critical overview of context, applications, and performance characteristics of cobalamin, methylmalonic acid, and holotranscobalamin II. Am J Clin Nutr. 2011;94(1):348S-58S.

49. McNulty H, Scott JM. Intake and status of folate and related B-vitamins: considerations and challenges in achieving optimal status. Br J Nutr. 2008; 99(Suppl 3):S48-54.

50. Schroder TH, Quay TAW, Lamers Y. Methylmalonic acid quantified in dried blood spots provides a precise, valid, and stable measure of functional vitamin B12 status in healthy women. J Nutr. 2014;144:1658-63.

51. Ubbink JB, Serfontein WJ, De Villiers LS. Stability of pyridoxal-5-phosphate semicarbazone: applications in plasma vitamin B6 analysis and population surveys of vitamin B6 nutritional status. J Chromatogr B Biomed Sci Appl. 1985;342:277-84. 
52. Blanton CA, Moshfegh AJ, Baer DJ, Kretsch MJ. The USDA Automated Multiple-Pass Method accurately estimates group total energy and nutrient intake. J Nutr. 2006;136(10):2594-9.

53. Suitor CW, Bailey LB. Dietary folate equivalents: interpretation and application. J Am Diet Assoc. 2000;100(1):88-94.

54. Kalmbach RD, Choumenkovitch SF, Troen AM, D'Agostino R, Jacques PF, Selhub J. Circulating folic acid in plasma: relation to folic acid fortification. Am J Clin Nutr. 2008;88(3):763-8.

55. Frosst P, Blom HJ, Milos R, Goyette P, Sheppard CA, Matthews RG, et al. A candidate genetic risk factor for vascular disease: a common mutation in methylenetetrahydrofolate reductase. Nature. 1995;10:111-3.

56. Shane B. Folate and vitamin B12 metabolism: overview and interaction with riboflavin, vitamin B6, and polymorphisms. Food Nutr Bull. 2008;29(2):S5-16.

57. Plumptre L, Masih SP, Ly A, Aufreiter S, Sohn K-J, Croxford R, et al. High concentrations of folate and unmetabolized folic acid in a cohort of pregnant Canadian women and umbilical cord blood. Am J Clin Nutr. 2015; 102:848-57.

58. Pfeiffer CM, Sternberg MR, Fazili Z, Yetley EA, Lacher DA, Bailey RL, et al. Unmetabolized folic acid is detected in nearly all serum samples from US children, adolescents, and adults. J Nutr. 2015;145(3):520-31.

59. Page R, Robichaud A, Arbuckle TE, Fraser WD, MacFarlane AJ. Total folate and unmetabolized folic acid in the breast milk of a cross-section of Canadian women. Am J Clin Nutr. 2017;105(5):1101-9.

60. Little RJ, Agostino RD, Cohen ML, Dickersin K, Emerson SS, Farrar JT, et al. The prevention and treatment of missing data in clinical trials. N Engl J Med. 2012;367(14):1355-60

\section{Publisher's Note}

Springer Nature remains neutral with regard to jurisdictional claims in published maps and institutional affiliations.

Ready to submit your research? Choose BMC and benefit from:

- fast, convenient online submission

- thorough peer review by experienced researchers in your field

- rapid publication on acceptance

- support for research data, including large and complex data types

- gold Open Access which fosters wider collaboration and increased citations

- maximum visibility for your research: over $100 \mathrm{M}$ website views per year

At BMC, research is always in progress.

Learn more biomedcentral.com/submissions 